\title{
Smart Healthcare and Value Co-creation: The Service Science Perspective to Healthcare Quality Improvements
}

\author{
Giuseppe Russo $^{1}$, Andrea Moretta Tartaglione ${ }^{1} \&$ Ylenia Cavacece $^{1}$ \\ ${ }^{1}$ Department of Economics and Law, University of Cassino and Southern Lazio, Cassino, Italy \\ Correspondence: Ylenia Cavacece, Department of Economics and Law, University of Cassino and Southern Lazio, \\ Cassino, Italy.
}

Received: August 24, 2019

Accepted: September 30, 2019

Online Published: October 14, 2019

doi:10.5430/ijba.v10n6.p1

URL: https://doi.org/10.5430/ijba.v10n6.p1

\begin{abstract}
This paper aims to identify efficient paths for improving healthcare service quality by adopting the theoretical framework of Service Science based on value co-creation and smart healthcare. Through a literary review, the links between healthcare quality, patient satisfaction and value co-creation are identified and analyzed from a smart healthcare perspective. Theoretical implications are tested through the analysis of the Lazio region case in Italy. The results make it possible to identify the possible positive effects on the quality of the health service deriving from the application of new management logics based on sharing and co-creating services between health professionals and patients by using the latest digital technologies. This work suggests the adoption of new logics, practices and technological tools that allow health managers to design experiences and services able to satisfy patients' different needs while benefiting from them through "win-win" solutions, able to create a higher value for all the actors involved in the healthcare process.
\end{abstract}

Keywords: healthcare quality, patient satisfaction, Service Science, smart healthcare, case study

\section{Introduction}

The sustainability of the Healthcare systems is a topic of current interest in the healthcare management literature for the strong tension that some factors of change are exerting on health expenditure such as the progressive aging of the population, the expansion of chronic degenerative diseases and the scarcity of public financial resources in several countries (Russo et al., 2019). These issues have shifted the focus from the well-being of citizens, and the satisfaction of their needs, towards the financial aspects of health management suggesting solutions usually addressed to mechanisms to cut funding and / or share the expenditure between public and private. These solutions are in contrast with the prevailing international strategic orientations, based mainly on the "centrality of the patient" in health management, on his/her involvement in the processes of prevention, treatment and rehabilitation and on the use of his opinions / needs (Moretta Tartaglione et al., 2018).

The complex organization of the healthcare systems, the number of actors, the ambitious pursuit of their purpose (public health), stimulates the deepening of the logics that can support the creation of value for the various actors involved and, of course, for the main beneficiary, i.e. the patient. In this context, various marketing logics have been applied to the study of healthcare management, among which Service Science. Service Science is an interdisciplinary field that "combines organization and human understanding with business and technological understanding to categorize and explain the many types of service systems that exist as well as how service systems interact and evolve to co-create value" (Maglio \& Spohrer, 2008, p. 18).

Nowadays the patient is more informed and educated, more selective and demanding and has a greater capacity for choice. The new patient requires greater capacity for value creation from healthcare organizations. This makes the health sector a highly competitive market (Barton, 2003), driven by consumers' demand to have a "system that respects their commitments, provides them with useful information and involves them in the decision-making process" (Wadwa, 2002).

According to a marketing perspective, healthcare organizations should consider patients as clients, because improving customer satisfaction has direct implications on quality - both in terms of services offered and reputation in perfectly meeting consumers' needs. Healthcare providers and patients are jointly responsible for service success and creating 
positive value for all stakeholders (Zainuddin et al., 2013). Therefore, value co-creation together with the patient has become more necessary than ever for the survival of the organization. Considering patients as clients in the health sector means recognizing that patients consciously choose the services to buy and the suppliers that best meet their needs (Wadhwa, 2002).

A healthcare organization's reputation for its commitment to quality and a patient-centered service is a key factor for individuals when choosing a healthcare provider (Stavins, 2006). Therefore, patient satisfaction should be a strategic goal for all healthcare organizations "(Stavins, 2006).

The patient represents a complex ecosystem of information that reinforces the idea of a patient-centered approach to health data management. Likewise, the role of health staff, as creator and first-rate beneficiary of patient information, should not be underestimated. Effective health events must be based on the efficient flow of patient information used to support clinical decision-making.

Service Science suggests address these issues by applying the latest Information and Communication Technologies (ICTs) to co-create value by facilitating the exchange of information and cooperation between all the actors involved in the healthcare provision, including the patient, in order to create a smarter healthcare.

This work analyzes this perspective with the aim of identifying efficient paths for improving healthcare service quality. The theoretical implications derived are tested through the analysis of the Lazio region case in Italy.

\section{Theoretical Background}

\subsection{Patient Satisfaction as Indicator of Healthcare Quality}

During the last decades, healthcare studies have shown that patient satisfaction is a strategic asset for improving organizations' quality (Reichheld, 2003). In particular, surveying satisfaction is an essential element of the quality assessment process (Barton, 2003; Quinn, et al., 2004) and, at the same time, quality improvement is aimed at satisfying patients' needs and expectations. The quality improvement process follows the quality assessment and uses the results to develop policies that can address the problems reported by customers (Barton, 2003), in order to achieve greater satisfaction.

Over the years there have been various definitions of patient satisfaction. Oliver (1981) defines it as the comparison between perceived performance and expectations. If the disconfirmation is positive (i.e., the perceived performance is greater than expected) then satisfaction is generated, otherwise - negative disconfirmation - dissatisfaction arises.

Susie Linder-Pelz (1982, p. 578) suggests the following definition: patient satisfaction is "... the combination of positive evaluations about distinct aspects of healthcare (the subject of the evaluation could be a single medical test, the treatment received during an illness, a particular care plan or the health system in general)".

Donabedian (1980) argues that the evaluation of quality by a patient - displayed by their satisfaction or dissatisfaction - can concern different aspects: "it could concern the properties of care services, aspects of technical management, the characteristics of interpersonal relationships and the physiological, physical, psychological or social consequences of a cure. A subjective synthesis and the balance of these detailed judgments would represent general satisfaction"(p. 25).

According to Palmer et al. (1991), healthcare quality can be defined as judgment made by the recipient of the treatment as weather their expectations have been met or not (Palmer et al. 1991). Generally patient satisfaction is defined as the degree of congruence between expectations for an ideal care and the perception of the actual care the patient receives.

Despite its widespread use, patient satisfaction was initially regarded as a difficult concept to measure and understand (Fitzpatrick and Hopkins, 1983). It is, in fact, a complex and multi-dimensional concept, related to both the technical and interpersonal aspects of assistance and healthcare facilities. The patient's judgment is very subjective and it is based on the perception of assistance that is related to "personal needs" rather than to universal standards. Therefore, the healthcare organization must measure, analyze and report at what level the adopted standards meet the patient's needs.

According to Oliver (1980), the quality of the service can be measured by the difference between the customer's expectations and their real experience after receiving the services - an experience better than expected makes customers leaning towards satisfaction.

Davis and Hobbs (1989) differentiate the several elements of customer satisfaction to be considered in order to obtain an accurate measurement. They classify these components in three different dimensions: 
- access to care (for example, directions within the health facility, waiting times, ward opening hours);

- environment (for example, neatness of the reception area, noise level and hygienic condition of the area where the treatment takes place);

- care received (i.e., human and clinical aspects, and the result).

Donabedian (1988), one of the most recognized experts in quality measurement, states: "patient satisfaction can be considered as one of the desired results of the treatment and also as an element of the health condition ... it is useless to discuss about the validity of patient satisfaction as a measure of quality. Whatever its strengths and its limits as an indicator of quality, information on patient satisfaction is crucial to make useful assessments to plan and manage the healthcare systems" (p. 1743).

\subsection{Links Between Value Co-creation and Patient Satisfaction}

Several studies show that the co-created value between patients and health staff can favor, among other things, customer satisfaction (Guenzi \& Troilo, 2007; Cedric Hsi-Jui, 2011; Dabholkar \& Sheng, 2012; Moretta Tartaglione et al., 2018). The co-creation process offers several social benefits for patients. Patients can, for example, improve their social status by being recognized as a source of valuable information by other involved parties. Furthermore, active participation in a community with people who share the same problems and interests improves communication skills and creates social contacts (Etgar, 2008). This process is accompanied by a feeling of pride due to the direct participation in the realization of a co-created value (Franke \& Schreier, 2010; Moreau \& Mandria, 2010). Franke et al. (2010, p. 125) define this concept as "I designed it myself effect", meaning the increase in value that an individual attributes to a self-designed object, which results exclusively from the fact that he/she feels like the creator of that object. Franke et al. (2010) further argue that this effect is based on the fact that subjective attributions often count more than the objective ones. However, they argue that "we do not know to what extent the feeling of having made a contribution is desirable" (Franke et al., 2010, p.137) and that the co-creation outcomes depend on the clients' assessment of their own contribution. The literature suggests that, when customer self-efficiency increases, the level of the effort made to create a service is no longer seen as a cost but rather contributes to the growth of customer value (van Beuningen et al., 2011). Applying this line of reasoning to the concept of co-creation, it can be argued that the customers' idea of value derives from the co-creation process and, as a consequence, their future behavior is determined by their evaluation of the part of success that can be attributed to themselves. This is consistent with the concept of decision satisfaction (Heitmann et al., 2007), which postulates that customers experience satisfaction or dissatisfaction not only with the service purchased but also with the purchase decision process in itself. The decision satisfaction is associated with the service development process and therefore goes beyond the satisfaction with the result. When the service is co-created and adapts to customers' needs, the effort made in the co-creation process is perceived as positive and complements the personal value attributed to the service. This happens because the efforts made in the co-creation process are perceived as a rewarding experience that goes beyond the evaluation of the service value (Franke \& Schreier, 2010). It can therefore be deduced that customers assess the co-creation process based on the degree to which they are satisfied with their own performance during the co-creation, seen as the satisfaction for participating in the realization of the service offer (for example, through feedback). In general, customers' assessment of their own contribution influences their evaluation of the general satisfaction with the service provider (Bendapudi \& Leone, 2003). If customers believe that the partners' contribution in value creation is not equally distributed, customer satisfaction with the organization decreases. Although the study of the consequences of co-creation is at an early stage, it is possible to argue that client participation increases motivation and commitment. These circumstances allow us to perceive a higher quality of service and that is an aspect directly related to satisfaction (Dong et al., 2008).

Although satisfaction was substantially understood as an individual judgment of performance with respect to an expectation (Hunt et al., 2012), a growing number of papers suggests that satisfaction assessments are social (Fournier \& Mick, 1999), proposing a change of approach from tangible resources to intangible resources, such as value co-creation and relationships (Vargo \& Lusch, 2004). As a matter of fact, the involvement of the client in the processes of value co-creation probably has consequences from the point of view of assessing satisfaction with the service. Thus, if we consider clients as active participants in the value co-creation process (Vargo \& Lusch, 2008), their greater satisfaction must be considered as a consequence (Grönroos, 2008).

After carrying out a study on the health sector in developing countries, Rehman and Dean (2010) find that there is a link between the patient's participation in the health service delivery process, the perceived quality of the service and value co-creation. 
The practical application of value co-creation in healthcare services could take place through the collection of patients' judgments about their degree of satisfaction with the service and the consideration of their feedback in strategies aimed at improving the quality of the service itself. When healthcare providers design services that meet the needs of as many users as possible they improve healthcare equity (Eriksson et al., 2016).

Elg et al. (2012) study the different ways through which health service providers can learn from patients. In particular, they suggest a model of value co-creation based on the use of diaries by patients. The authors run a test on 53 patients to verify the usefulness of that tool for the value co-creation. The results show that the diary model can be used as a tool for the generation and collection of patients' ideas, to illustrate the history of an individual patient, to stimulate the development of new healthcare services and the creation of a patient-centered care, and to improve the understanding of how the patient experiences health services.

Even patient complaints should not be considered just as a post-consumer judgment but should be taken as an opportunity for co-creating value that can increase the patient's awareness of service perceptions (Olsson, 2016). However, these practices require healthcare professionals to improve their interpersonal skills, allowing patients and relatives to provide feedback during service interaction about their satisfaction or dissatisfaction. Furthermore, the provider should interact with the entire customer value creation network, which may also include knowledge and skills from other sources, such as relatives (Olsson, 2016).

Some studies point out that the healthcare value must be conceptualized from an experiential point of view (Mathwick et al., 2001). Value co-creation implies integration and sharing of the different meanings of value attributed by the various actors (doctors and patients). For example, Osei-Frimpong et al. (2016) argue that patients consider the value received from the service in terms of not only health improvements, but also in terms of their experience in the consultation room. Thus, the value perceived by patients is linked to their experiences during visits (hedonistic value), while doctors consider the value more from the functional point of view (utilitarian value) (Osei-Frimpong et al., 2016).

Helkkula et al. (2013) examine how different actors calculate the value of experience within public health service systems, distinguishing between the calculated value, which is commonly obtained by observing changes in specific clinical measures, and personal value, which is based on individual sense-making in a social context.

By involving the customer, it is possible to achieve an end service that is completely adapted to the needs of the customers thus increasing their satisfaction.

\subsection{Value Co-creation in Service Science}

A very important theory for understanding value co-creation is Service Science, originally promoted and developed by the IBM Almaden Research Center in the United States of America.

Service Science is an interdisciplinary field that "combines organization and human understanding with business and technological understanding to categorize and explain the many types of service systems that exist as well as how service systems interact and evolve to co-create value" (Maglio \& Spohrer, 2008, p. 18).

Service Science aims to integrate business-related disciplines such as management, operations, marketing and IT (Bitner and Brown, 2006) with engineering and computer science (Chesbrough \& Spohrer, 2006), focusing on service as a central interest (IFM and IBM, 2007). It focuses on the study of value co-creation within and between Service Systems, defined as configurations of people, technology, value propositions and shared information capable of co-creating value, such as languages, laws, measurements and methods (Spohrer et al. 2007), within complex constellations of integrated resources (Spohrer et al., 2007, 2008).

Maglio and Spohrer (2008) define service systems as (p. 18): "the smallest service system is the individual, and the largest service system includes global economy. Cities, businesses, corporate departments, nations, government agencies are all service systems. Each service system is at the same time a supplier and a customer of the service, connected through value proposals to networks or systems that create value".

Service systems interact with each other to co-create value (Spohrer et al. 2007; 2008). Maglio et al. (2010, p. 1) argue that Service Science is the "systematic search for principles and approaches that can help understand and improve all types of value co-creation". Thus, value and value creation are central to the service and are fundamental to understand the dynamics of service systems and promoting Service Science.

Value co-creation interactions between service systems are service interactions. Each service system engages in three main activities that make up a service interaction: (1) to propose an interaction of value co-creation to another service system (proposal), (2) to accept a proposal (agreement), and (3) to implement the proposal (realization). 


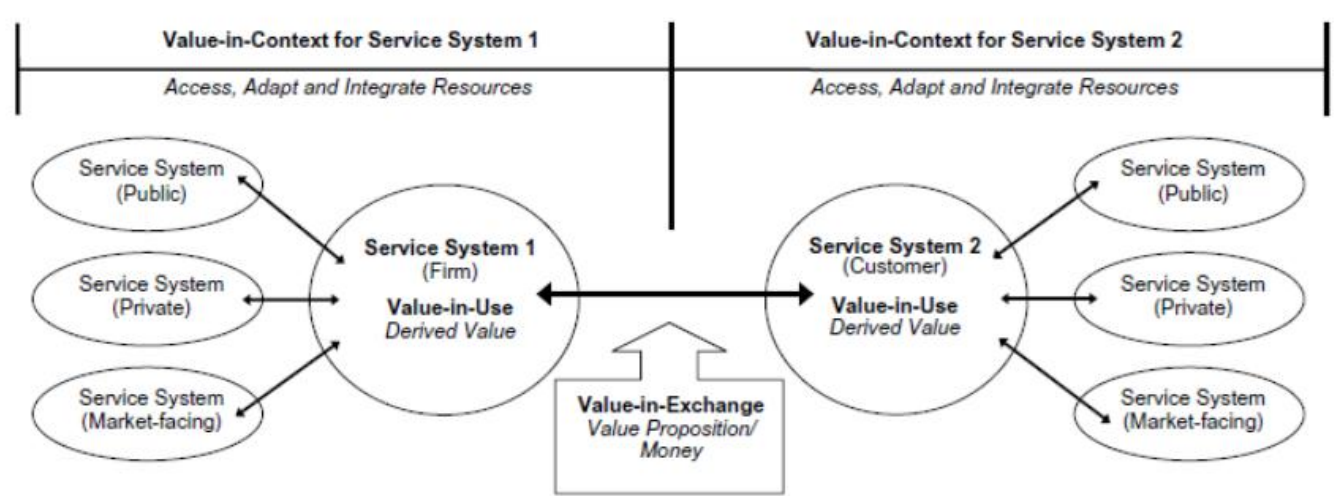

Figure 1. Value co-creation between service system

Source: Vargo et al., (2008)

The value proposition is accepted, rejected or ignored by other service systems that need resources. The proposed service can be provided directly or indirectly through an asset. Once the value is proposed and the service made available on the market, it is up to other service systems - potential customers - who need those resources to decide whether or not to accept the value proposition.

The agreed proposals can be successfully implemented and with mutual satisfaction for both service systems, or they may not produce the results desired by one or both service systems. This definition provides a useful perspective for understanding economic phenomena, arguing that value is created in a collaborative manner within interactive configurations of mutual exchange.

The Service-Dominant logic (S-D logic) (Vargo \& Lusch 2004; 2008), with its definition of service as the application and exchange of resources and competences for the benefit of others within paths of value co-creation, was soon recognized as a basic theoretical foundation for the development of Service Science and the study of service systems (Maglio \& Spohrer 2008).

As Maglio and Spohrer (2008, p. 19) suggest, the S-D logic provides "the right perspective, the vocabulary and the hypotheses on which to build a theory of service systems, their configurations and modes of interaction. In short, the S-D logic can be considered the philosophical foundation of Service Science and the service system could be its basic theoretical construction". Thus, both Service Science and S-D logic lead to a systemic nature of value creation.

In particular, from the point of view of Service Science, co-creation is at the center of the theoretical development of a science of service systems (Vargo et al., 2008; Ostrom, 2010; Maglio et al., 2009) rooted in the S-D logic (Lusch \& Vargo, 2006; Ballantyne \& Varey, 2008) and strongly oriented towards innovation (Bitner et al, 2006).

Although the concepts of value co-creation and Service Science have been widely used in industrial services, their application in healthcare services still remain in the theoretical and experimental phase and more details on how to change patient participation into available data that will contribute to improvements of the healthcare service system need to be discussed (Zhang et al., 2015).

Beverungen et al. (2019) call for more research aimed at studying smart service systems that use simple appliances to provide smart service for smart living or smart healthcare in business-to-consumer contexts.

Several scholars ask for more studies on how smart service systems could also be used to analyze dynamic interactions between stakeholders (Solaimani et al., 2013) and the collaboration with other service providers, such as physicians and health insurance companies (Davenport \& Lucker, 2015).

Based on these considerations, this paper offers a contribution by analysing the SMART approach to healthcare of Service Science and testing the theoretical implications through a case study showing how smarter applications can be used to improve the quality of the healthcare system of a region.

\section{Research Method}

This paper adopts a qualitative method consisting in two different phases: 1) the SMART approach to healthcare is applied to the analysis of the major healthcare issues and solutions with the aim of finding a match between theory 
and reality; 2) a case study was conducted in order to test the conceptualizations derived in the first phase in a concrete case. According to the methodology of Yin (2003), the case study has been conducted by seeking to triangulate data through the intersection of different sources of data. Primary data has been collected through a semi-structured interview with a manager of the Lazio region, and integrated and compared with secondary data extracted from several documents, such as the website, statements and reports. To ensure internal validity, we used protocols for the development and formalization of the case study; to get external validity we used analytical generalization based on Yin (2003).

\section{Findings and Discussion}

\subsection{The SMART Approach to Healthcare of Service Science}

In agreement with Maglio and Spohrer (2008), it is believed that the service system is a useful abstraction for understanding value co-creation in the health sector as well.

Based on the definition of service system provided by Spohrer et al. (2007), the health system can easily be defined as a service system. Indeed, it consists of different actors, including:

- Institutional actors (local health units, hospitals, districts, nursing homes, municipalities, voluntary associations), who are entrusted with the care and provision of services;

- Other national and local organizations for the planning and control (Region, State, local authorities) that collaborate in the assistance and the provision of services;

- Actors responsible for the medical-scientific training (Regions and Autonomous Provinces, professional associations, scientific societies, trade union associations and universities);

- The citizens;

- Suppliers of goods and services for healthcare companies.

These actors represent a set of connected and interacting parties that have a common goal: the health of the community. The possibility to interact allows them to improve the level of their performance and the service offered for everyone benefit according to a win-win logic. To reach the goal, the different parties continuously share resources and information, supported along the process by the use of new technologies.

Providing healthcare services means that doctor and patient have to work together to create value. When a doctor interviews the patient, runs some tests and prescribes a medicine, the patient answers the questions, collaborates by going for the exams and takes the drug as prescribed. It is possible that during the exams' stages or prescriptions, technologies and other people are involved co-creating value - in this case represented by the patient's health. These relationships and dependencies can be seen as a system of interacting parties. In many cases, a service system is a complex type of system - a system in which the parties interact with each other in a non-linear way. As such, a service system is not just the sum of its parts. The complex interactions between the various parties create a system that acts according to schemes that are difficult to predict.

In recent years, Service Science research is focusing on intelligent service systems (SMART), stimulated by technological advances and the most recent proposals on IT systems. Smart service systems can be defined as service systems that are specifically designed for the cautious management of their activities and objectives, able to self-reconfigure themselves to guarantee their ability to continue to satisfy the relevant actors. They are mainly (but not only) based on ICTs as enablers of reconfiguration and intelligent behavior with the aim of creating a basis for systematic service innovation (IFM and IBM, 2008) in complex environments (Basole \& Rouse, 2008; Demirkan et al., 2008). The origin of the concept is based on IBM's proposal for advanced ICTs for a smarter planet, which implies that Information and Communication Technologies must tackle problems in a more intelligent and reactive way, with a profound implication that consists in the dynamism and the adaptation to the rapid changes that characterize today's world. Therefore, ICT for a smarter planet is a project that proposes reliable and intelligent technologies capable of reconfiguring their structure, activities and objectives in order to maintain the state of balance over time in the face of external changes.

Smart service systems are based on interactions, links and experiences between the actors. Of course, among those actors, customers play a key role. When they ask for personalized products/services, they demand very fast reactions and high levels of service quality. Despite the relevance of the customer, which indirectly influences every participating actor, smart service systems must deal with the behavior of every other actor, whose expectations, needs and actions directly influence the development of the system and its future configurations. 
The smart approach applied to healthcare is called "smarter healthcare". As IBM highlights, a smarter healthcare system is achieved through better links for faster and more detailed data analysis. Many of the current problems - rising costs, limited access, high error rates, poor response to chronic patients and the long cycle of new drug development could be overcome by improving the links between diagnosis, pharmaceutical research, health professionals, patients, taxpayers and communities. Unfortunately, current healthcare IT systems have been designed to provide faster and better performance for doctors in patient treatment, and not to integrate and aggregate data for analysis, research and reporting.

Smarter healthcare converts patients and clinical information into viable insights to improve care quality, optimizing operational efficiency. By providing integrated data from multiple sources in a single central location, technology platforms can help enable a more informed decision-making process within and between clinics, companies and research sectors, leading to higher quality care, greater safety for the patient and more efficient clinical and business operations (Carrubbo et al., 2015). Doctors, patients and tax payers can easily and efficiently share information, applying advanced analysis to improve research, diagnosis and treatments (www.research.ibm.com/healthcare).

In short, smarter healthcare means creating a smarter, more connected health system that can provide better care with fewer errors, predict and prevent disease, allow people to make better choices and apply clinical, business and technology experience to create solutions that integrate clinical competence with information technology. Through smarter healthcare, it would be possible to empower patients to make more informed decisions about taking care of themselves or their lifestyle. In addition, pharmaceutical, medical devices and health insurance companies could use analytical tools to extract new information from their data in order to reduce risks, predict trends and increase patient satisfaction.

IBM provides several solutions for more instrumental, interconnected and intelligent systems, including:

- Connected home for people with chronic illnesses

- Healthcare data management

- Collaboration Agenda for health plans

- Business analysis software for healthcare
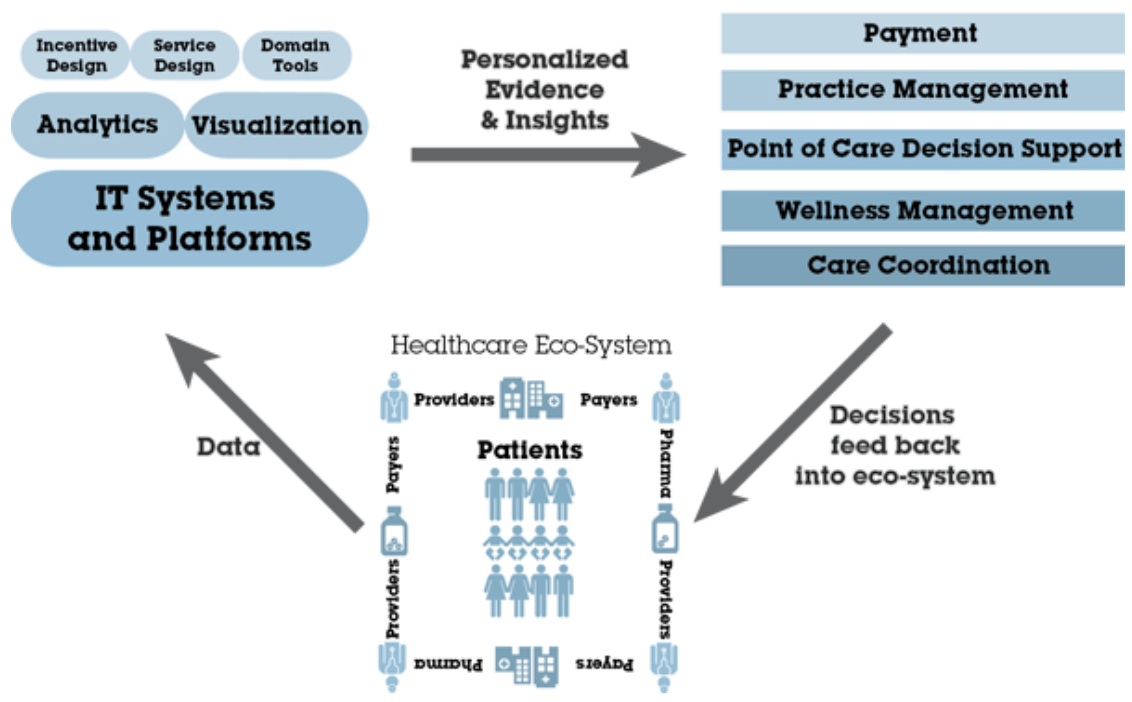

Figure 2. Healthcare smart service system

Source: http://www.research.ibm.com/healthcare

Therefore, technological platforms and ICT solutions play an important role based on value co-creation in service science because they are able to facilitate interaction and sharing information between the various actors involved.

From value co-creation point of view, the role of platforms and technology should not be to provide health care services but to support patients in self-managing their condition. For example, Buranarach et al. (2011), from a Service 
Science perspective, describe two service systems designed to support self-care activities of patients with type 2 diabetes: an automated telephone disease management system (ATDM) and a support portal for patient self-management. In the treatment of chronic disease, improving patient self-management can lead to improved user co-creation and participation in the service system. Service systems supporting patient self-management must focus on user personalization, i.e., services personalization.

\subsection{The Case of the Lazio Region in Italy}

The sustainability of the Italian health system is at risk: the elderly population is growing ( $34 \%$ of the population will be over 65 by 2050), the needs and demand for care (especially the chronic one) increase and resources are increasingly limited (health expenditure equal to about $8.9 \%$ of GDP, below the European average). In this context, the Italian Government has identified the smart healthcare as the main solution for winning the challenge of sustainability in the healthcare sector.

The Italian Health Service is a system of organizations and services that have the purpose of guaranteeing the health and wellbeing of all citizens, under conditions of equality, universal access and equitable provision of health services. Its functionality is based on the respect of three fundamental principles: Universality - the extension of health services to the whole population; Equality - citizens must access the healthcare services without any distinction of individual, social and economic conditions; Equity - all citizens must be guaranteed equal access in relation to equal health needs. The Central government and the Regions have legislative powers for the healthcare management. The Central Government establishes the general guidelines and determines the minimum performance levels that must be guaranteed throughout the national territory. While the Regions plan and manage healthcare in their area in full autonomy but always in compliance with the objectives and directives established at central level.

Within the three-year plan for the health ecosystem, the Central Government has highlighted three projects for a smarter healthcare that the Regions must complete:

1. Electronic Health Record (ESF), through which citizens can trace, consult and share their health history;

2. Single reservation center (CUP), a centralized computerized system for the unified booking of services, to facilitate the accessibility of assistance and the reduction of waiting times in order to simplify the interaction between the Public Administration and the citizen;

3. Telemedicine, a project to offer services that improve the usability of care, diagnosis services and remote medical advice, as well as constant monitoring of vital parameters through new technologies.

The Lazio region is among the most important Italian regions. In fact, it has Rome as its capital and includes the Vatican State. With 5.879.082 inhabitants, it is the second most populated region of Italy after Lombardy, and the ninth for geographical extension (ISTAT, 2019). The healthcare of the Lazio region is the one that presents the greatest sustainability problems. During the last 10 years, the staff of the Lazio health system has been reduced considerably: it has lost 16 hospitals, $14 \%$ of staff and 3,600 beds (finishing below the national average of 3 beds per thousand residents); currently the Lazio facilities have only seven health operators per thousand inhabitants (OASI, 2018). Waiting times in the Emergency Room have increased (28.5 minutes). All this has had serious repercussions on the quality of the healthcare service and on the satisfaction of the citizens. In fact, in the Lazio region there is a record of passive mobility, that is, of citizens who go to other regions to access healthcare services (10.3\%). In order to improve the quality of healthcare and regain the satisfaction of citizens, the Lazio region, in line with the national guidelines, decided to invest in smart healthcare projects, aimed at improving the efficiency of services through new technologies that allow paths of value co-creation among the various actors, including patients. These projects belong to the "Regional Health Information System of Lazio (SISR)" program, which is the organizational and technological reference framework for the complex of activities, including administrative and management, of the regional health system aimed at guaranteeing better services for citizens, reducing health management costs and implementing a more extensive expenditure control. The needs of citizens are the starting point for the redefinition of an integrated government system of health, which uses digital technologies to provide innovative services and improve the existing ones, allowing healthcare to be accessed effectively and simply. The most significant implemented projects are described below:

Single Regional Health Registry. It is a single database including all the Health Information Systems of the Lazio region. It aims to facilitate collaboration and information exchange between the various actors involved in health management (Region, Ministry, hospitals, local health units, doctors and users) by bringing together all the information recorded by the various institutes or organizations into a single database constantly checked and updated. 
LazioHealth App. It is the app of the Lazio Region that allows citizens to consult, in a geo-localized way, the health facilities in the Lazio region: First Aid, Primary care clinics, Vaccination centers, Health Houses, Medical Guard and Pharmacies. The goal is to offer citizens practical and immediate information on the nearest health facilities based on the user's geolocation. Through the App it is possible to view the nearest health facilities on the map, by selecting the radius of distance in $\mathrm{km}$, and possibly start the guided navigation towards the selected structure.

Digitalization of reports. It is a service aimed at digitalizing the patients' reports that citizens can download on the regional health portal. This service allows the reports availability at any time of the day and on any day of the week, from any device connected to the Internet; safe, because the document obtained digitally is intact, non-perishable, produced and protected according to the regulations in force, including those concerning the protection of personal data; eco-friendly, which respects the environment, reducing the printed word and the movement of citizens; smart, because it reduces queues and waiting times at local units.

The Electronic Health Record. It aims to collect and store data and documents related to the clinical history of each citizen in digital format accessible not only by the citizen, but also by other appropriately authorized health information systems. It makes available the health and clinical information generated during the processes of prevention, diagnosis and treatment of people allowing the users to be able to enter personal data and documents through the access interface.

The Cancer Registry. It is a centralized regional register, which collects cases of cancer of the adult and child population. The goal is to have information of high clinical and epidemiological value at individual and population levels, linking all the information related to a single patient with a cancer diagnosis, and to provide the clinician with a complete patient report. The aim is to identify incidents cases through specific algorithms able to automatically record cases for which sufficient information is available from current information systems, and to send other cases to manual registration. The web platform is also the tool that allows the peripheral functional units to read and code the cases of their competence for which it was not possible to proceed with automatic closure.

The Digital Recipe (E-Prescription). It is an integrated system of functions aimed at the complete dematerialization and management of the entire prescriptive-provisioning flow, through the integration and sharing of databases containing information on the Regional Health Service clients. It constitutes the "container" that collects all the electronic health prescriptions (pharmaceutical and specialist) of the prescribing physicians of the Lazio region.

Lazio Telemedicine. It consists in the provision of remote health services using information and telecommunications technologies in order to exchange information useful for the diagnosis, treatment and prevention of diseases and to guarantee continuous information to healthcare providers supporting the research and evaluation of care. Telemedicine services include the use of advanced technologies for the detection of vital parameters and patient health data and their transmission in the form of texts, sounds, images or other forms necessary for prevention, diagnosis, treatment and subsequent control of patients.

The main areas of application of telemedicine are:

- Homecare - providing healthcare at the patient's home through the monitoring and acquisition, in the home environment, of some vital parameters that in real time allow the health organizations and related personnel to analyze, control and act by preventing and solving any problems arising from the surveys in progress.

- Teleconsulting - carry out remote medical consultations between specialists, using equipment connected to computer systems (in particular for radiology, cardiology and laboratory analysis) in order to make correct diagnoses, compare information on treatment and prevention pathways, as well as for training medical and paramedical staff.

The Territorial Assistance Information System (SIAT). It was created to support the network of local services, developing a strong integration among all the service participants, improving and speeding up the circulation of information for the provision of increasingly effective services, guaranteeing a minimum standard homogeneous among all the structures of the regional territory. The SIAT, as a support tool for territorial health districts, providers and regional structures, is organized in modular components, interconnected and integrated, and ensures the management of the entire process of definition, provision and monitoring of the home care services.

\section{Conclusions and Implications}

Looking at the healthcare system from the Service Science perspective, it is possible to understand the contribution of the many actors (including patients) involved in providing health services, the mutual influences, the effects of network cooperation and the win-win logic (Capunzo et al., 2013). Mutual exchange between service providers and users imposes the logic of value co-creation. The health organization, drawn up within the framework of systemic 
relationships, can be defined as a system (Golinelli, 2000; 2005), as a part of a broad context that opens its borders to the external environment (Barile et al, 2012) by tightening relationships with the different actors who work in there (Golinelli et al, 2002; Barile, 2008). The real and effective interaction between the various operators, organizations and communities, necessarily involves the participation of different parties in the process of co-creation of a sustainable value that benefits everyone. To be effective and productive, those same parties must necessarily collaborate, and must do it constantly, in a bijective way, in a reticular form, with the aim of increasing everyone's level of performance thus contributing to the growth of the system as a whole (Polese \& Capunzo, 2013). Within the health system, each actor (considered an integral and active part of the system) must act in a functional and effective way, in relation to their personal goals, also through the development of specific innovative processes and, inevitably, must contribute to the improvement of the quality level of the system as a whole (Barile et al., 2012).

Creating value with patients entails the need for suppliers to understand patients' needs or objectives and adopt a holistic approach in order to generate positive experiences and strengthen and increase patients' confidence in consultations (Osei-Frimpong, 2016). The patient's needs significantly influence the patient-doctor relationship (approach to the administration of care, level of trust and propensity to shared Decision-Making). This in turn influences the experiential value perceived by the patients and their assessment of satisfaction (Osei-Frimpong, 2016). In particular, managers should recognize that patients vary in motivation and behavior and consequently they should develop strategies relevant to patients' lifestyles. For example, two patients can be alert to physical fitness, but one prefers fitness classes that can be attend with others, while the other prefers to train alone at home. So, managers can design different service experiences to satisfy different consumer lifestyles (Chandler \& Chen, 2016).

The adoption of a Smart orientation in healthcare promoted by the Service Science, suggests the use of the latest digital technologies for the value co-creation and patient satisfaction. The case analyzed in this work highlights how the Lazio region in Italy has implemented strategies based on the digital technologies to improve the quality of the health services provided in order to recover the patient satisfaction and ensure the sustainability of the regional healthcare system. The solutions analyzed in the case study are all based on ICT technologies that allow increasing the exchange of information and cooperation between all the actors involved in the healthcare provision as well as the active participation of the patients in the process according to a value co-creation view. The results of the case study are in line with the relevant literature.

Wells et al. (2013), for example, studying the case of medical device companies, conclude that they are able to achieve a better understanding of their customers and create a more efficient relationship with them by aligning the perception of value, the needs and the expectations of the customer with their own, and creating personalized experiences based on mutual understanding (Wells et al., 2015). To that, they have to add investments in technology that allow and support the processes of value co-creation (Sukkird \& Shirahada, 2015). Rantala and Karjaluoto (2016) show how online platforms represent a new form of interaction for value co-creation, where both parts are independent but the service (through the digital platform) is available on an ongoing basis and significantly differs from the traditional situations of occasional meetings between service provider and patient. This continuity over time through digitization allows a paradigm shift. Loane et al. (2014) examine the mechanisms of value co-creation that are generated in online health communities, which more and more consumers are turning to for information on health and social assistance. The results show that online healthcare communities offer consumers the ability to create and benefit from forms of customer value that would not be available in a traditional healthcare system (Saarni, 1999). Van Oerle et al. (2016) identify four online community configurations based on the levels of cognitive and emotional value creation, the types of community activities, the patients involved, the professionals and other stakeholders and the levels of data disclosure by members of the communities: (1) providers of basic information, (2) advanced aggregators of patients' knowledge, (3) systematic network innovators, and (4) mere publishers of ideas. The results demonstrate that the creation of cognitive value is a driving force for creation of emotional value. Black and Sahama (2016) foresee that the introduction of personally controlled electronic health record (PCEHR) will provide the infrastructure and the push to improve information flows in clinical practices and the service quality.

The results of this study suggest to healthcare managers create secure, dynamic and affordable technology platforms to support access to information throughout the patient's life and cooperation between professionals and patients. The result is a transition from sporadic clinical encounters to a continuous cycle of care that optimizes healthcare quality and patient satisfaction.

\section{References}

Ballantyne, D., \& Varey, R. J. (2008). The service-dominant logic and the future of marketing. Journal of the Academy of Marketing Science, 36(1), 11-14. https://doi.org/10.1007/s11747-007-0075-8 
Barile, S. (2008). L'impresa come sistema. Contributi sull'approccio sistemico vitale. Torino: Giappichelli.

Barile, S., Polese, F., Saviano, M., Carrubbo, L., \& Clarizia, F. (2012). Service Research Contribution to Healthcare Networks. Innovative Service Perspectives, Hanken School of Economics.

Barton, P. L. (2003). Understanding the U.S. health services system: Second edition. Washington, D.C.: AUPHA.

Basole, R. C., \& Rouse, W. B. (2008). Complexity of Service Value Networks Conceptualization and Empirical Investigation. IBM Systems Journal, 47, 53-68. https://doi.org/10.1147/sj.471.0053

Bendapudi, N., \& Leone, R. P. (2003). Psychological Implications of Customer Participation in Co-Production. Journal of Marketing, 67(1), 14-28. https://doi.org/10.1509/jmkg.67.1.14.18592

Beverungen, D., Müller, O., Matzner, M., Mendling, J., \& Vom Brocke, J. (2019). Conceptualizing smart service systems. Electronic Markets, 29, 7-18. https://doi.org/10.1007/s12525-017-0270-5

Bitner, M. J., \& Brown, S. W. (2006). The Evolution and Discovery of Services Science. Business Schools, Communications of the ACM, 49(7), 73-78. https://doi.org/10.1145/1139922.1139952

Buranarach, M., Thatphithakkul, N., Kawtrakul, A., Wongrochananan, S., Kulnawan, N., \& Jiamjarasrangsi, W. (2011). Development of service systems to support diabetes patient self-management using a personalized service framework. Proceedings - 2011 Annual SRII Global Conference, SRII 2011, 363-370. https://doi.org/10.1109/SRII.2011.49

Capunzo, M., Polese, F., Boccia, G., Carrubbo, L., Clarizia, F., \& De Caro, F. (2013). Advances in Service Research for the understanding and the management of service in healthcare networks. In E. Gummesson, C. Mele, \& F. Polese (Eds.), Service-Dominant Logic, Network \& Systems Theory and Service Science: integrating three perspectives for a new Service Agenda. Napoli: Giannini Editore.

Carrubbo, L., Bruni, R., Cavacece, Y., \& Moretta, T. A. (2015). Service System Platforms to Improve Value Co-Creation: insights for Translational Medicine. In E. Gummesson, C. Mele, \& F. Polese (Eds.), Service Dominant Logic, Network and Systems Theory and Service Science: Integrating three Perspectives for a New Service Agenda. Napoli: Giannini Editore.

Cedric, H-J. W. (2011). A re-examination of the antecedents and impact of customer participation in service. The Service Industries Journal, 31(6), 863-876. https://doi.org/10.1080/02642060902960768

Chesbrough, H., \& Spohrer, J. (2006). A Research Manifesto for Services Science. Communications of the ACM, 49, 35-40. https://doi.org/10.1145/1139922.1139945

Dabholkar, P. A., \& Sheng, X. (2012). Consumer participation in using online recommendation agents: effects on satisfaction, trust, and purchase intentions. The Service Industries Journal, 32(9), 1433-1449. https://doi.org/10.1080/02642069.2011.624596

Davenport, T. H., \& Lucker, J. (2015). Running on data. Deloitte Review, 16, 5-15.

Davis, D., \& Hobbs, G. (1989). Measuring outpatient satisfaction with rehabilitation services. Quality Review Bulletin, 15, 192-197. https://doi.org/10.1016/S0097-5990(16)30291-3

Demirkan, H., Kauffman, R. J., Vayghan, J., Fill, H-G., Karagiannis, D., \& Maglio, P. P. (2008). Service-oriented technology and management: Perspectives on research and practice for the coming decade. Electronic Commerce Research and Applications, 7(4), 356-376. https://doi.org/10.1016/j.elerap.2008.07.002

Donabedian, A. (1980). The Definition of Quality and Approaches to its Assessment. Ann Arbor, MI: Health Administration Press.

Dong, B., Evans, K. R., \& Zou, S. (2008). The effects of customer participation in co-created service recovery. Journal of the Academy Marketing Science, 36, 123-137. https://doi.org/10.1007/s11747-007-0059-8

Elg, M., Engström, J., Witell, L., \& Poksinska, B. (2012). Co-creation and learning in health-care service development. Journal of Service Management, 23(3), 328-343. https://doi.org/10.1108/09564231211248435

Etgar, M. (2008). A Descriptive Model of the Consumer Co-Production Process. Journal of the Academy of Marketing Science, 36, 97-108. https://doi.org/10.1007/s11747-007-0061-1

Fitzpatrick, R., \& Hopkins, A. (1983). Problems in the conceptual framework of patient satisfaction research: an empirical exploration. Sociology of Health and Illness, 5(3), 297-311. https://doi.org/10.1111/1467-9566.ep10491836

Fournie, S., \& Mick, D. G. (1999). Rediscovering Satisfaction. Journal of Marketing, 63, 5-23. https://doi.org/10.1177/002224299906300403 
Franke, N., \& Schreier, M. (2010). Why Customers Value Self-Designed Products: The Importance of Process Effort and Enjoyment. Journal of Product Innovation Management, 27(7), 1020-1031.

Franke, N., Schreier, M., \& Kaiser, U. (2010). The "I Designed It Myself" Effect in Mass Customization. Management Science, 56, 125-140. https://doi.org/10.1111/j.1540-5885.2010.00768.x

Golinelli, G. M. (2000). L'approccio sistemico al governo dell'impresa. L'impresa sistema vitale. Padova: Cedam.

Golinelli, G. M. (2005). Approccio sistemico al governo dell'impresa. Padova: Cedam.

Grönroos, C. (2008). Service logic revisited: who creates value? And who co-creates?. European Business Review, 20(4), 298-314. https://doi.org/10.1108/09555340810886585

Guenzi, P., \& Troilo, G. (2007). The joint contribution of marketing and sales to the creation of superior customer value. Journal of Business Research, 60, 98-107. https://doi.org/10.1016/j.jbusres.2006.10.007

Heitmann, M., Lehmann, D. R., \& Herrmann, A. (2007, May). Choice Goal Attainment and Decision and Consumption Satisfaction. Journal of Marketing Research, XLIV, 234-250. https://doi.org/10.1509/jmkr.44.2.234

Helkkula, A., Kelleher, C., \& Pura, M. (2012). Characterizing Value as an Experience Implications for Service Researchers and Managers. Journal of Service Research, 15(1), 59-75. https://doi.org/10.1177/1094670511426897

Hunt, L. A., Mcgee, P., Gutteridge, R., \& Hughes, M. (2011). Assessment of student nurses in practice: A comparison of theoretical and practical assessment results in England. Nurse Education Today, 32(4), 351-355.

IfM \& IBM. (2007). Succeeding through Service Innovation: A Discussion Paper. Cambridge, United Kingdom: University of Cambridge.

ISTAT. (2019). Retrieved from http://dati.istat.it/Index.aspx?DataSetCode=DCIS_POPRES1

Linder-Pelz, S. U. (1982). Toward a theory of patient satisfaction. Soc Sci Med., 16(5), 577-82. https://doi.org/10.1016/0277-9536(82)90311-2

Loane, D. J., Stoica, B. A., Tchantchou, F., Kumar, A., Barrett, J. P., Akintola, T., ... Faden, A. I. (2014). Novel mGluR5 positive allosteric modulator improves functional recovery, attenuates neurodegeneration, and alters microglial polarization after experimental traumatic brain injury. Neurotherapeutics, 11(4), 857-869. https://doi.org/10.1007/s13311-014-0298-6

Lusch, R. F., \& Vargo, S. L. (2006). Service-dominant logic: reactions, reflections and refinements. Marketing Theory, 6(3), 281-288. https://doi.org/10.1177/1470593106066781

Maglio, P. P., \& Spohrer, J. (2008). Fundamentals of service science. Journal of the Academy of Marketing Science, 36(1), 18-20. https://doi.org/10.1007/s11747-007-0058-9

Maglio, P. P., Kieliszewski, C. A., \& Spohrer, J. C. (2010). Introduction: Why a handbook? In Maglio, P. P., Kieliszewski, J. A., Spohrer, J. C. (Eds.), Handbook of Service Science (pp. 1-7). New York: Springer. https://doi.org/10.1007/978-1-4419-1628-0_1

Maglio, P. P., Vargo, S., Caswell, L. N., \& Spohrer, J. (2009). The service system is the basic abstraction of the service science. Information Systems and $E$ Business Management, 7(4), 395-406. https://doi.org/10.1007/s10257-008-0105-1

Mathwick, C., Malhotra, N., \& Rigdon, E. (2001). Experiential value: Conceptualization, measurement and application in the catalog and internet shopping. Journal of Retailing, 77(1), 39-56. https://doi.org/10.1016/S0022-4359(00)00045-2

Moretta, T. A., Cavacece, Y., Cassia, F., \& Russo, G. (2018). The excellence of patient-centered healthcare: Investigating the links between empowerment, co-creation and satisfaction. The TQM Journal, 30(2), 153-167. https://doi.org/10.1108/TQM-11-2017-0138

OASI. (2018). RAPPORTO OASI 2018 - Osservatorio sulle Aziende e sul Sistema sanitario Italiano. Milano: SDA Bocconi, School of management. Retrieved from http://www.cergas.unibocconi.eu/wps/wcm/connect/224a071c-c555-4557-b845-de75277b1ade/Rapporto+OASI +2018_Executive+Summary.pdf?MOD=AJPERES\&CVID=mtVqeK6

Oliver, R. L. (1981). Measurement and evaluation of satisfaction process in retail settings. Journal of Retailing, 75(3), 25-48. 
Olsson, E. M. (2016). Interpersonal complaints regarding cancer care through a gender lens. International Journal of Health Care Quality Assurance, 29(6), 687-702. https://doi.org/10.1108/IJHCQA-03-2014-0032

Osei-Frimpong, K. (2016). Examining the effects of patient characteristics and prior value needs on the patient-doctor encounter process in healthcare service delivery. International Journal of Pharmaceutical and Healthcare Marketing, 10(2), 192-213. https://doi.org/10.1108/IJPHM-01-2016-0005

Ostrom, E. (2010). Beyond markets and states: Polycentric governance of complex economic systems. Amer. Econom. Rev., 100(6), 1-33. https://doi.org/10.1257/aer.100.3.641

Palmer, R. H., Donabedian, A., \& Povar, G. J. (1991). Striving for Quality in Health Care: An Inquiry into Policy and Practice. Chicago, IL: Health Administration Press.

Quinn, G. P., Jacobsen, P. B., Albrecht, T. L., Ellison, B. A., Newman, N. W., Bell, M., \& Ruckdeschel, J. C. (2004). Real-time patient satisfaction survey and improvement process. Hospital Topics, 82(3), 26-32. https://doi.org/10.3200/HTPS.82.3.26-32

Rantala, K., \& Karjaluoto, H. (2016). Co-creation in health care: Insights into the transformation from value creation to value co-creation through digitization. Proceedings of the 20th International Academic Mindtrek Conference, 34-41. https://doi.org/10.1145/2994310.2994325

Rehman, M., \& Dean, A. M. (2010). A proposed model of the links between consumer participation, perceived service quality and customers' perceptions of value co-creation. International Research Symposium in Service Management, 24-27.

Reichheld, F. F. (2003). The one number you need to grow. Harvard Business Review, 81(12), 46-54.

Russo, G., Moretta, T. A., \& Cavacece, Y. (2019). Empowering patients to co-create a sustainable healthcare value. Sustainabilty, 11(5), 13-15. https://doi.org/10.3390/su11051315

Solaimani, S., Guldemond, N., \& Bouwman, H. (2013). Dynamic stakeholder interaction analysis: innovative smart living design cases. Electronic Markets, 23(4), 317-328. https://doi.org/10.1007/s12525-013-0143-5

Spohrer, J., Maglio, P. P., Bailey, J., \& Gruhl, D. (2007). Steps toward a science of service systems. Computer, 4O(1), 71-77. https://doi.org/10.1109/MC.2007.33

Spohrer, J., Vargo, S., Caswell, N., \& Maglio, P. (2008). The Service System is the Basic Abstraction of Service Science. 41st Annual HICSS Conference Proceedings. https://doi.org/10.1109/HICSS.2008.451

Stavins, C. L. (2006). Developing employee participation in the patient satisfaction process. ACHE: Fellowship Case Reports.

Van Beuningen, J., de Ruyter, K., \& Wetzels, M. (2011). The power of self-efficacy change during service provision: Making your customers feel better about themselves pays off. Journal of Service Research, 14(1), 108-125. https://doi.org/10.1177/1094670510379037

Van Oerle, S., Mahr, D., \& Lievens, A. (2016). Coordinating online health communities for cognitive and affective value creation. Journal of Service Management, 27(4), 481-506. https://doi.org/10.1108/JOSM-09-2015-0264

Vargo, S. L., \& Lusch, R. F. (2004). Evolving to a new dominant logic for marketing. Journal of Marketing, 68(1), 1-17. https://doi.org/10.1509/jmkg.68.1.1.24036

Vargo, S. L., Maglio, P. P., \& Akaka, M. A. (2008). On value and value co-creation: A service systems and service logic perspective. European Management Journal, 26, 145-52. https://doi.org/10.1016/j.emj.2008.04.003

Wadwha, S. S. (2002). Customer satisfaction and health care delivery systems: Commentary with Australian bias. The Internet Journal of Nuclear Medicine, 1(1), 1539-4638. https://doi.org/10.5580/15d7

Wells, R., Gallarza, M. G., Andreu, L., \& Calero, R. (2013). Application of Service Dominant Logic to the Medical Device Industry. Proceedings EGPA Annual Conference, Edinburgh.

Zainuddin, N., Russell-Bennett, R., \& Previte, J. (2013). The value of health and wellbeing: an empirical model of value creation in social marketing. European Journal of Marketing, 47(9), 1504-1524. https://doi.org/10.1108/EJM-10-2011-0564

Zhang, L., Tong, H., Demirel, H. O., Duffy, V. G., Yih, Y., \& Bidassie, B. (2015). A practical model of value co-creation in healthcare service. Procedia Manufacturing, 3, 200-207. https://doi.org/10.1016/j.promfg.2015.07.129 